\title{
The City Hall of Mirandola Hardly Hit by the Earthquake of 2012: Damage Assessment and Approaches for the Seismic Improvement
}

\author{
M. Bonariol, G. Boscato, A. Dal Cin, D. Fiorotto, and S. Russo
}

\begin{abstract}
The City Hall of Mirandola was stricken and damaged by Emilia-Romagna earthquake sequence of May 2012. The research suggests solutions for the rehabilitation of a masonry historic building that presents a serious damage pattern. The solutions includes the base isolation of the global structure. Through the historical analysis, the damage survey and the mechanisms analysis were defined the macro-structure of the palace. Subsequently, was generated different configurations based on the aggregation or separation of the five macro-structure identified. The separation of these proposed projects is done through the use of seismic isolators and dampers. It was carried out a simplified finite element model and the linear elastic dynamic modal analysis was performed to evaluate the main modes of vibration of each configuration, which correspond to the higher values of percentage of participating mass. Finally a response spectrum analysis was performed with the use of data of the earthquake of 29 May 2012. It going to evaluate the seismic behavior of all the configurations.
\end{abstract}

Index Terms-Monuments, damage survey, collapse mechanisms, seismic rehabilitation project.

\section{INTRODUCTION}

Concern has grown in the last years in Italy about the assessment of preservation state of monuments and historic town centers, due to the presence of a rich historic-architectural heritage which must face a multiplicity of risk factors due to extreme actions or degradation processes generated by natural or human actions [1]. The historic-architectural heritage in seismic zone is mainly focused on, especially after the last severe earthquakes. Awareness is also growing in zones of relatively low seismic risk, where there is a need to extend the knowledge of historic buildings in order to check the current state of preservation and set up ad hoc guidelines for maintenance. In fact, the available information on buildings and structures of great historic-artistic importance can be scanty or inaccurate due to the lack of documentation about construction phases and past interventions [2]-[4].

Computer-based structural control techniques are now a well-known resource for the preservation of cultural heritage

Manuscript received April 15, 2014; revised June 18, 2014.

M. Bonariol and D. Fiorotto are with IUAV University of Venice, 30123 Venice, Italy (e-mail: michela.bonariol@libero.it, davidefiorotto@libero.it).

G. Boscato and A. Dal Cin are with IUAV University of Venice, Laboratory of Strength of Material (LabSCo), Via Torino 153/a, 30121 Venice, Italy (e-mail: gboscato@iuav.it, adalcin@iuav.it).

S. Russo is with IUAV University of Venice, Dept of Design in Complex Environments Dorsoduro 2206, 30123 Venice, Italy (e-mail: russo@iuav.it). buildings; in such cases, data acquisition from remote is especially suitable for long-term monitoring of static and dynamic structural parameters [5], [6]. Cultural heritage buildings are unique and sensitive assets, especially where critical conditions of damage or decay are present; the advantages of this kind of monitoring must thus be exploited with programs designed for the specific case. Modal identification techniques are used to estimate the dynamic properties of a structure based on experimental data. This technique has gained significant importance because it is an important step for model updating techniques, structural health monitoring [7]-[9] and damage prognosis.

The rehabilitation of the historic construction it is very sensitive. Unfortunately, in the recent past have been made invasive interventions with unsuitable materials such as the recent interventions found in the subject of this research. Nowadays, the expert pay more attention to this issue and trying to use innovative materials lighter [10]-[12].

\section{MiRANDOLA's EARTHQUAKE}

The Emilia-Romagna has been subject to an important seismic sequence in May 2012, a powerful quake of magnitude $5.8 \mathrm{Ml}$ and depth of hypocenter $9.6 \mathrm{~km}$ was recorded at 09:00:03 on 29 May 2012. The epicenter was in the Medolla and Cavezzo in the province of Modena.

Each component of the waveform of the earthquake was registered at the Mirandola's station. In Table I have been reported the principal values of the accelerograms, in detail the values of local magnitude (Ml), of depth, of distance from epicenter and of the maximum PGA (peak ground acceleration) recorded for each components (N-S, E-W and UP).

TABLE I: THE ARRANGEMENT OF CHANNELS

\begin{tabular}{|c|c|c|c|c|c|}
\hline Station & $\begin{array}{l}\text { Seismic } \\
\text { event }\end{array}$ & $\begin{array}{l}\text { Magnitude } \\
\text { Ml }\end{array}$ & $\begin{array}{l}\text { Depth } \\
{[\mathrm{km}]}\end{array}$ & Chanel & $\begin{array}{l}\text { PGA } \\
{[\mathrm{cm} / \mathrm{s} 2]}\end{array}$ \\
\hline \multirow{3}{*}{$\begin{array}{l}\text { Mirandola } \\
\text { MRN }\end{array}$} & \multirow{3}{*}{$\begin{array}{l}\text { May } 29 \\
2012\end{array}$} & \multirow{3}{*}{5.8} & \multirow{3}{*}{9.6} & NS & 290 \\
\hline & & & & EW & 220 \\
\hline & & & & UP & 900 \\
\hline
\end{tabular}

The direction of maximum compression in place that is approximately the direction north-south. Observing the horizontal components of motion (Table I), the most interesting value is the $\mathrm{N}-\mathrm{S}$ component that seems the most severe $(\mathrm{PGA}=290 \mathrm{~cm} / \mathrm{s} 2)$. However the highest value $(\mathrm{PGA}=900 \mathrm{~cm} / \mathrm{s} 2)$ is recorded by the vertical component caused by the important manifestation of the primary wave $P$, 
due by the small distance from the epicenter (Table I).

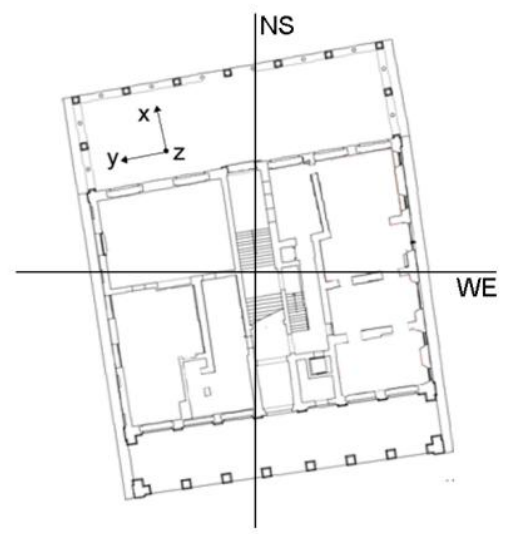

Fig. 1. Plans of the palace with the indication of the N-S and E-W directions.

The damage surveys of the palace confirm that the larger displacements of the entire building have occurred along the $\mathrm{x}$ axis (Fig. 1).

\section{BUILDING DESCRIPTION AND DAMAGE SURVEY}

The City Hall is a masonry historic building that lies in the center of the city of Mirandola (Fig. 2). The first building was expanded in the north part in 1468 with a Renaissance style part overlooking Piazza Mazzini and in 1748 was added a loggia in the south side (Fig. 1). At the end of the nineteenth century the building was restored and the loggia was completely destroyed and rebuilt.

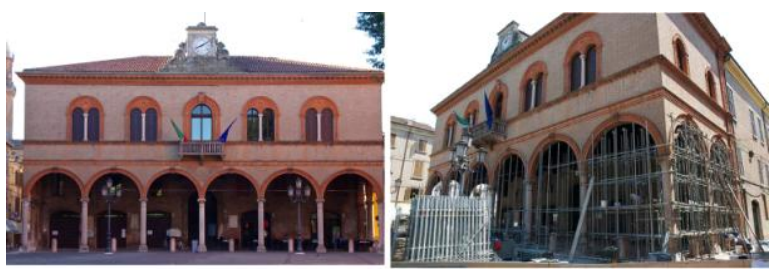

Fig. 2. View of the City Hall pre and post earthquake.

The earthquake has severely affected the structure. The loggia has been a northward shift that resulted in the posting of this part from the main volume. The back wall has many vertical cracks that indicate a crushing of the masonry due to the stress of the overlying loads (a heavy steel cover's structure of a recent restoration) that have gone to weigh in this longitudinal wall. The columns of the loggia have well reacted to the seismic action. The side arches of the loggia present cracks in the cornices due to the displacement along their main axis (x) (Fig. 1) which led the formation of hinges.

The main room 'Sala Granda' has suffered several cracks, particularly along the shorter side walls. Observing Figure 3 the trend of the crack is visible inclined, it propagates from the opening of the shorter side wall up to the facade. The displacement of the greater mass of the entire building to the north has caused an overturning mechanism of the facade.

The volume of the important staircase presents a very serious crack pattern (Fig. 4), the lesions were detected particularly along the longer sides on the east and west probably because the higher NS seismic component caused larger displacements of the entire building along the $\mathrm{x}$ axis
(Fig. 1). The collapse of the plaster in some areas of the perimeter walls allows us to analyze the texture of the walls and conseguently of the crack below. The presence of multiple lesions $45^{\circ}$ inclined, often by sliding joints suggest a collapse of shear type. Some lesions very deep propagate throughout the height of the volume.
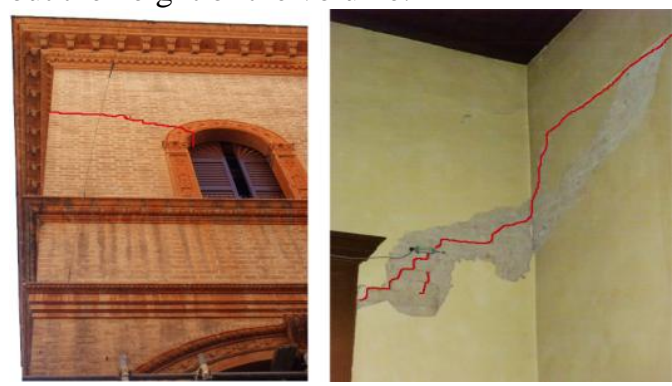

Fig. 3. View of the inclined crack of the overturning mechanism of the facade.

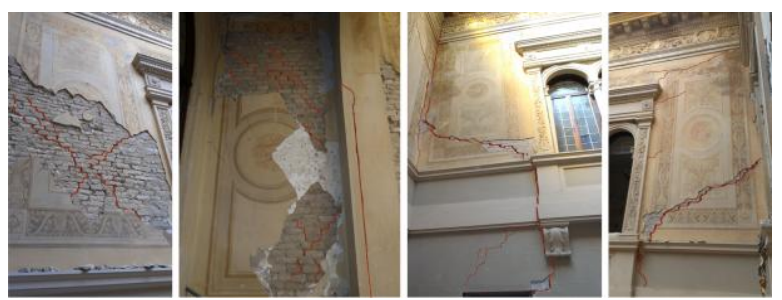

Fig. 4. View of the damaged pattern of the perimeter wall of the staircase.

The main volume presents serious cracks that have occurred in the centrepiece and in the bearing wall. The main structure has full-height vertical and diagonal cracks induced by compression and buckling.

\section{Seismic Performance Improvement of the Palace}

The Italian Guide Lines for the assessment and mitigation of seismic risk of cultural heritage [13] give directions for the evaluation and mitigation of seismic risk to cultural heritage.

These rules, generally regard the individual parts of the structure, trying to avoid altering the original distribution of the mass and stiffness. Some of the elements present in the palace suffered many invasive restorations that have worsened the seismic response.

In front of the devastating seismic response of the building have emerged questions: why continue to make it more rigid and heavy construction when this has already led to severe damage? Why do not choose instead the lightness and elasticity, even in historic buildings as is usual in new buildings? (Fig. 5)

Frank Lloyd Wright "An American Architecture" in 1955 referring to the Imperial Hotel in Tokyo, built by him in 1920 and withstood numerous earthquakes, wrote: "We solved the problem of the menace of the quake by concluding that rigidity couldn't be the answer, and that flexibility and resiliency must be the answer ... Why fight the quake? Why not sympathize whit it and out wit it?"

As for the light, the proposal is to replace the steel beams of the roof and the floors structures with pultruded beams, fiber-reinforced composite material that weighs $80 \%$ less than steel with the same strength. Have been calculated the loads of a floor with steel beams and brick of the city hall, equal to $2.96 \mathrm{KN} / \mathrm{m}^{2}$. This result was compared with those of 
a floor in pultruded beams, equal to $1.4 \mathrm{KN} / \mathrm{m}^{2}$, demonstrating a decrease of more than $50 \%$ in exchange of only a slight variation in the package thickness of $5 \mathrm{~cm}$ (Fig. $6)$.

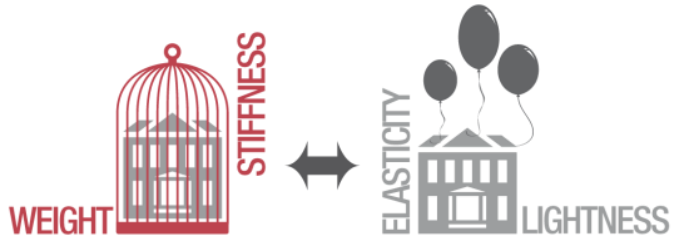

Fig. 5. Concept of intervention strategy.
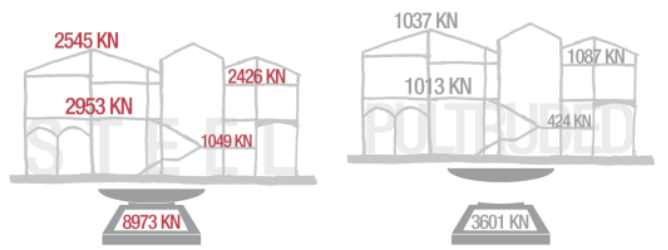

Fig. 6. Comparison of the weights of the floors.

It is important to remember that the town hall was the result of the aggregation of several structures, hence the idea to ensure that these masses have the ability to move separately rather than working as a rigid box.

It is therefore proposed to separate and reconnect through the damper the different masses (Fig. 7), so try to dampen the vibrations and ensure that the bodies move separately without damage, or at least lessening the severity of the cracks.

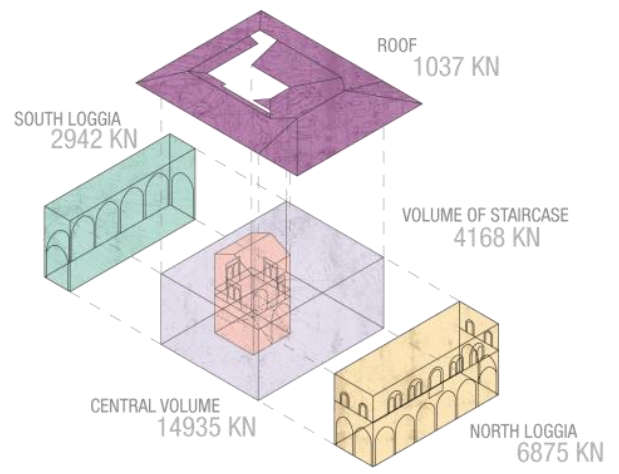

Fig. 7. The different masses that compose the building.

Thanks to an in-depth historical analysis, to the analysis of the damage survey and the failure mechanisms, it was possible to identify the macro-structure that constitute the palace. Subsequently, different possible configurations are then generated based on the aggregation or separation of the five previously identified masses.

Were therefore hypothesized different configurations: a single mass, regarded as stiffening of the global construction and its subsequent isolation at the base (Fig. 8), two masses, respectively, going to isolate the North loggia, the staircase or the roof, three masses and finally to four masses, so considering all of the macro-structures separated. It was made a selection of these configurations based on the previous analysis.

With reference mainly to the analysis of the damage were examined four of the proposed project alternatives, in which the separation through seismic isolators and dampers, of the masses would lead to a different seismic response of the palace (Fig. 9).

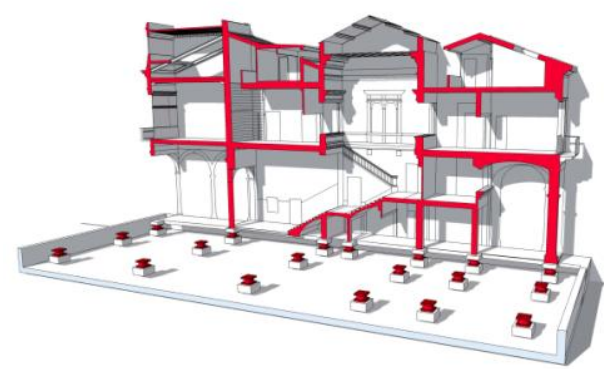

Fig. 8. Base isolation.
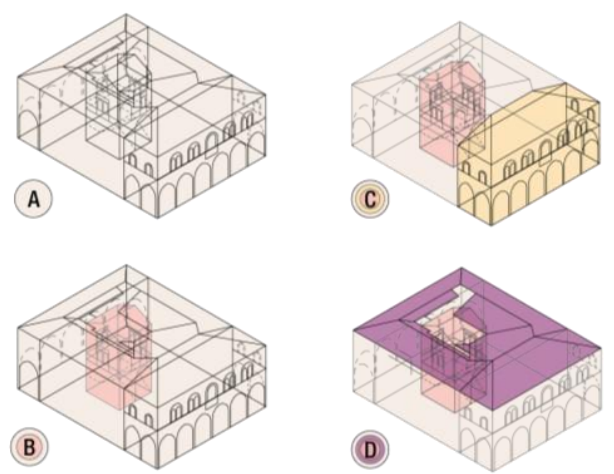

Fig. 9. The four configurations examined in the analysis.

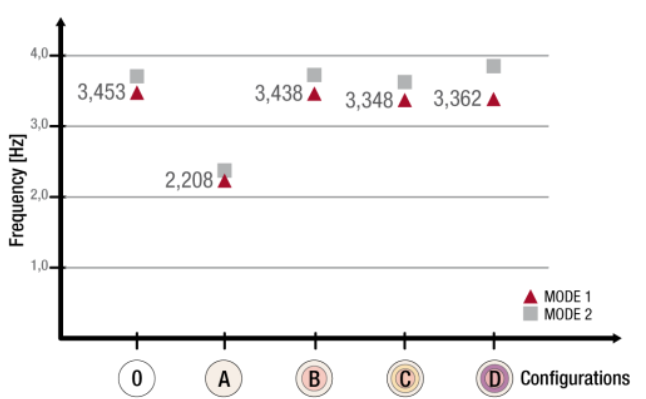

Fig. 10. Graphic analysis of the frequencies.

For each proposed intervention was analyzed the eccentricity between the center of gravity of the masses and center of stiffness, which revealed that the lowest value is obtained with the base isolation of the global structure or with the separation of the staircase from the rest of the structure.

It was then carried out a dynamic analysis, linear elastic, on a simplified finite element model of the city hall.

The elastic moduli and the geometry were assigned to each horizontal and vertical elements of the FE model, which represents the state of the structure before the earthquake.

The dynamic modal analysis was performed to evaluate the main modes of vibration of each configuration, which correspond to the higher values of percentage of participating mass.

In the initial configuration is considered a perfect fit to the base while the one with the isolation at the base of the joint has been replaced with springs in the three directions, whose stiffnesses were redefined in order to reach those of the perfect fit and then cut by $50 \%$.

The outcome of the analysis of the frequencies of the structure in its different configurations, it is possible to observe constancy in the values for the three alternatives (Fig. 
10). The initial configuration presents the first frequency of $3.453 \mathrm{~Hz}$, a value that can be considered acceptable compared with that resulting from the identification test conducted on the data collected by the structural monitoring, completed in the months after the earthquake, which is equal to $2.73 \mathrm{~Hz}$. Finally, it is possible to confirm that the first configuration, as expected, is characterized by a strong reduction of frequencies, due to the isolation at the base.

As regards the main displacements, corresponding to the three bodies analyzed, occur in the $\mathrm{Y}$ direction, mostly concentrated in the upper part of the city hall in the North facade and in the floors in contact with the structure of the staircase (Fig. 11).

Subsequently, we analyzed the structure subjected to earthquake ground motion generated by the directions of the North-South and East-West of the earthquake of 29 May 2012, going to evaluate the outcomes of the displacements in the $\mathrm{X}$ and $\mathrm{Y}$ (the horizontal direction of the earthquake) in the three points of the model, in all the different configurations.

The results show that the critical part of the structure with the larger displacements appears to be the north face at the level of the "Sala Granda", supported only by marble columns. This is not found in the configuration with three masses with separation staircase and loggia, which, however, presents a high stress concentration on the part of the wall in contact with the roof (Fig. 12).

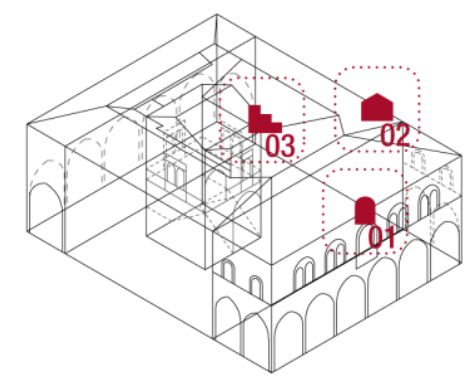

Fig. 11. Reading points for movements and stresses.

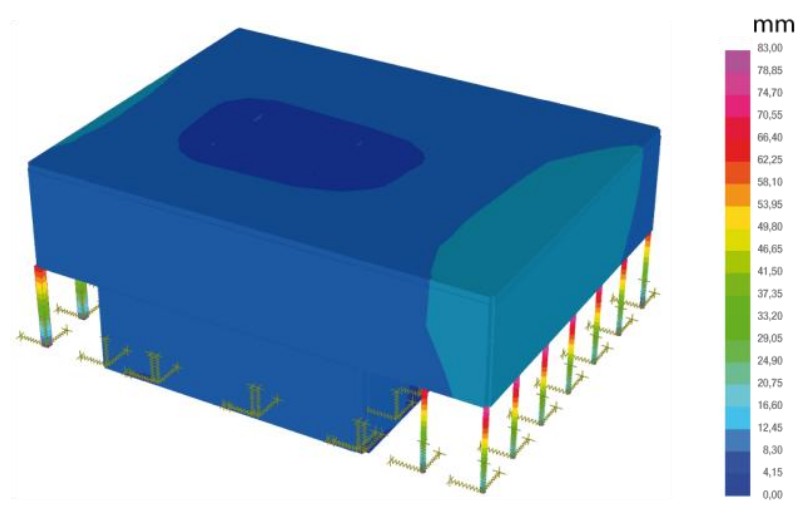

Fig. 12. FEM model of the structure subjected to earthquake ground motion with base isolation.

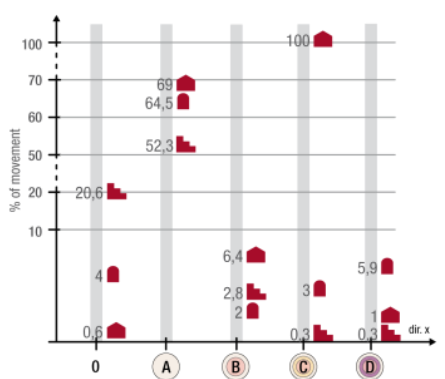

Fig. 13. Displacements analysis in $X$-direction.

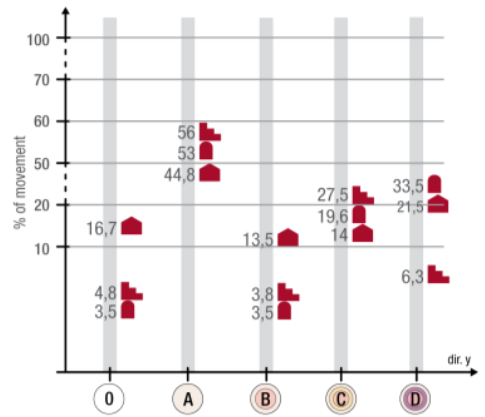

Fig. 14. Graphic movement's analysis in $Y$-direction.

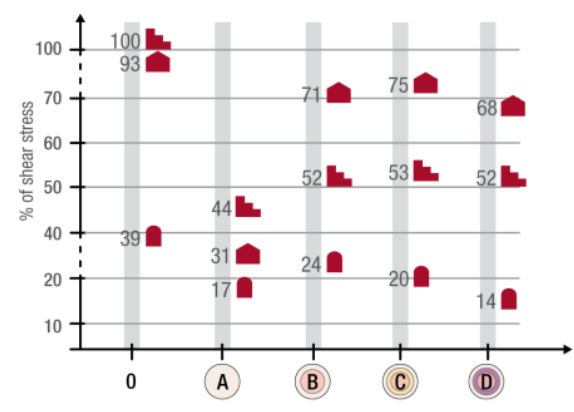

Fig. 15. Graphic stress analysis.

\section{CONCLUSION}

From the graphs of the displacements (Fig. 13, Fig. 14) can be seen that:

1) Base isolation obviously involves higher values compared to the initial configuration as isolators change the constraint on the floor of the palace and then allow a lower transmission of acceleration in both directions, and therefore less stress;

2) In the $X$ direction will generally have smaller displacements as the structure is more rigid than the action in the $Y$ direction;

3) In the $X$ direction higher displacements are obtained for configuration with three masses, in detail with the separation of the staircase and the loggia, because it offers lower inertia and because the displacements are amplified by torsional effects activated by the asymmetry in the plan;

4) In the $Y$ direction the volumes of the different configurations have displacements consistent with each other;

In addition, was performed of the shear stress analysis in the plane of the masonry perimeter walls at $1 \mathrm{~m}$ from the ground in axis with respect to the three bodies considered in the previous analysis.

The graph (Fig. 15) shows that:

1) Data derived from the analysis of the stresses in cutting plate confirm the considerations made for the move;

2) The four different configurations cut down about $40 \%$ of the base shear stresses to the structure's city hall and the loggia, and $20-25 \%$ of those of the staircase;

3) The solution of the base isolation is the best, major shifts correspond to less stress for the isolated structure to the ground;

4) The separation of the gallery or the roof, compared to only staircase leads to a slight decrease in shear stress, 
although the result is not decisive for the choice of the most advantageous proposal.

Finally, it possible to confirm that the best solution appears to be the base isolation; alternatively leads to advantages although the configuration consisting of three masses staircase, hall and also with the separation of the loggia.

With this research it was shown that it is probably better to change the ordinary process of approach to these issues, or at least introduces some innovative features, to get better results both in emergency management, both in the reconstruction and retrofitting of buildings.

\section{ACKNOWLEDGMENT}

For this research have been used scientific equipment acquired by the University IUAV of Venice within the project Iuav_lab, IUAV laboratories of innovation for architecture, the project is co-financed by the Veneto Region as part of the POR-CRO, the ERDF, 2007-2013, 1.1.1.

\section{REFERENCES}

[1] S. Russo and F. Sciarretta, "Masonry exposed to high temperatures: Mechanical behaviour and properties," Fire Safety Journal 2012, 2013.

[2] S. Russo, "Testing and modelling of dynamic out-of-plane behaviour of the historic masonry façade of Palazzo Ducale in Venice, Italy," Engineering Structures, vol. 46, 2013, pp. 130-139, 2012.

[3] G. Boscato, G. Riva, S. Russo, and F. Sciarretta, "ND tests for a first assessment of mechanical behaviour of the stone-covered façades of palazzo ducale in venice," in Proc. 12th International Conference on Structural Repairs and Maintenance of Heritage Architecture 2011, September 2011 Chianciano Terme, Italy, WIT Transactions on the Built Environment, vol. 118, pp. 615-625.

[4] G. Boscato, A. Dal Cin, G. Riva, S. Russo, and F. Sciarretta, "Knowledge of the construction technique of the multiple leaf masonry façades of Palazzo Ducale in Venice with ND and MD tests," Advanced Materials Research, vols. 919-921, pp. 318-324, 2014.

[5] S. Russo, "On the monitoring of historic Anime Sante church damaged by earthquake in L'Aquila," Structural Control and Health Monitoring, 2012.

[6] G. Boscato, D. Rocchi, and S. Russo, "Anime Sante Church's dome after 2009 L'Aquila earthquake, monitoring and strengthening approache," Advanced Material Research, vol. 446-449, pp. 3467-3485, 2012.

[7] G. Milani, S. Russo, M. Pizzolato, and A. Tralli, "Seismic behavior of the San Pietro di Coppito Church Bell Tower in L'Aquila," Open Civil Engineering Journal, pp. 131-147, 2012.

[8] G. Boscato, M. Pizzolato, S. Russo, and A. Tralli, "Seismic behaviour of a complex historical church in L'Aquila," International Journal of Architectural, 2012.

[9] G. Boscato, A. Dal Cin, S. Russo, and F. Sciarretta, "SHM of historic damaged churches," Advanced Materials Research, vol. 838-841, pp. 2071-2078, 2014.

[10] G. Boscato and S. Russo, "Dissipative capacity of FRP spatial pultruded structure," Composite Structures, 2014

[11] G. Boscato and S. Russo, "Free vibration of pultruded FRP elements: Mechanical characterization, analysis and applications," Journal of Composites for Construction ASCE, vol. 13, no. 6, pp. 565-574, 2009.

[12] S. Russo, "Performance of a PFRP structure covering a historic building struck by an earthquake," Advanced Composites in Construction 2011, pp. 51-57, 2011.

[13] Directive of the Prime Minister dated on 9/02/2011, Assessment and mitigation of seismic risk of cultural heritage with reference to the Building Code for the design of constructions, 2008

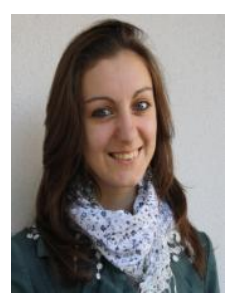

M. Bonariol was born in Vittorio Veneto (TV, Italy) on September 24, in 1989. She was graduated in architecture at Iuav University of Venice, Italy, in 2014.

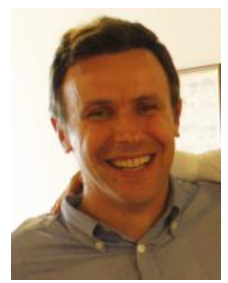

G. Boscato was born in Vicenza (Italy) on August 29, in 1972. He was graduated in architecture at Iuav University of Venice, Italy, in 2001. He received his $\mathrm{PhD}$ in economics and techniques for the Conservation of the Architectural and Environmental Heritage, University of Nova Gorica, Slovenia, in 2009. In 2004, 2005, 2009 he gained three research grants at Iuav University of Venice. His teaching experience at Iuav University of Venice started from 2003 as teaching assistant and from 2010 to 2014 as teacher on annual contract. Graduate Technician since 2011 at LabSCo (Laboratory of Strength of Materials) IUAV University of Venice. His research interests include the structural behaviour of new material and methodologies of structural health monitoring of historic building.

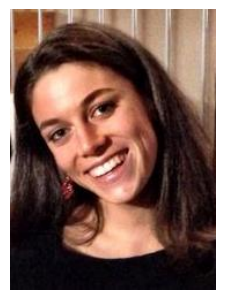

A. Dal Cin was born in Vittorio Veneto (TV, Italy) on Jennuary 15, in 1986. She has been Graduated in Architecture at Iuav University of Venice, Italy, in 2011. She was $\mathrm{PhD}$ student in structural rehabilitation of historical and modern buildings, University of Brescia, Italy. Her research interests include the methodologies of structural health monitoring of historic building. I am author of more than 10 national and international journal papers.

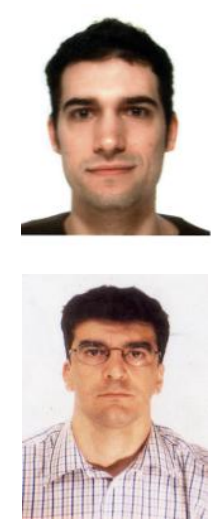

D. Fiorotto was born in Treviso (TV, Italy) on Augus 21 , in 1988 . He has been graduated in architecture at Iuav University of Venice, Italy, in 2014. of Torcello". In 2001, he succeeded in the national competitive examination for the position of Associate Professor of Structural Civil Engineering, and IUAV University of Venice then appointed him in 2002 In 2007 , he got the first book published in Italy on the structural use of thin fiber-reinforced composite pultruded members. He is an author of 158 scientific items. In 2006, he started collaborating to the editing of the National Research Council Technical Document (CNR DT) 2005/2007 on the structural use of thin fiber-reinforced composite pultruded members. Since 2009, he is an elected member of the Academic Senate of IUAV University of Venice. Since 2010, he is the director of the Laboratory of Strength of Materials at IUAV University of Venice. In 2008, he received an international award as the author of 'Best scientific paper'. Since 1998 he takes part in international cooperative scientific researches. 